\title{
MicroRNA-142-3p Induces Atherosclerosis- Associated Endothelial Cell Apoptosis by Directly Targeting Rictor
}

\author{
Bing Qin ${ }^{a}$ Yaqing Shu ${ }^{a}$ Ling Long ${ }^{a}$ Haiyan Lia Xuejiao Men ${ }^{a}$ Li Feng ${ }^{b}$ \\ Huan Yang ${ }^{b}$ Zhengqi Lu \\ aDepartment of Neurology, The Third Affiliated Hospital of Sun Yat-sen University, Guangzhou, \\ 'Department of Neurology, Xiangya Hospital, Central South University, Changsha, China
}

\section{Key Words}

Microrna-142-3p • HAECs • Apoptosis • Rictor • Atherosclerosis

\begin{abstract}
Background/Aims: Atherosclerosis, a multifactorial chronic disease, is the main cause of death and impairment in the world. Endothelial cells (ECs) apoptosis plays a crucial role in the onset and development of atherosclerosis, whereas the underlying molecular mechanisms are unclear. MicroRNA-142-3p (miR-142-3p) is a well-defined tumor suppressor in several types of cancer, while the role of miR-142-3p in ECs apoptosis and the development of atherosclerosis has yet to be elucidated. Therefore, the present study aimed to investigate the role of miR142-3p in ECs apoptosis during atherosclerosis and the underlying mechanism. Methods: Human aortic endothelial cells (HAECs) were treated with oxidized low-density lipoprotein (ox-LDL). The expression level of miR-142-3p was detected using qRT-PCR. Apoptosis was determined via flow cytometry and Caspase-3 activity assay. Prediction of the binding between miR-142-3p and 3'-UTR of Rictor mRNA was performed by bioinformatics analyses and confirmed by a dual luciferase reporter assay. The effects of miR-142-3p on endothelial apoptosis and atherosclerosis were further analyzed in an in vivo model using ApoE $\mathrm{E}^{-/-}$mice fed with high-fat diet (HFD). Results: MiR-142-3p expression was substantially up-regulated during the ox-LDL-elicited apoptosis in HAECs. Forced expression of miR-142-3p exacerbated apoptosis in ECs whereas inhibition of miR-142-3p could partly alleviate apoptotic cell death mediated by ox-LDL. Further analysis identified Rictor as a direct target of miR-142-3p, and Rictor knockdown abolished the anti-apoptotic effect of miR-142-3p inhibitor. Moreover, the Akt/endothelial nitric oxide synthase (eNOS) signaling pathway was found to mediate the beneficial effect of miR-142-3p inhibitor on endothelial apoptosis. Finally, systemic treatment with miR-142-3p antagomir attenuated endothelial apoptosis and retarded the progression of atherosclerosis in the aorta of $\mathrm{ApoE}^{-/-}$mice. Conclusions: Down-regulation of miR-142-3p inhibited ECs apoptosis and atherosclerotic development by up-regulating the expression of Rictor and activating the Akt/eNOS signaling pathway. This indicates that miR-142-3p may be a potential target for the prevention and treatment of atherosclerosis.

(C) 2018 The Author(s) Published by S. Karger AG, Basel

Zhengqi Lu Department of Neurology, The Third Affiliated Hospital of Sun Yat-sen University No. 600 Tianhe Road, Guangzhou, Guangdong, 510630 (China)

Tel. +86-20-85252238, Fax +86-20-87567133, E-Mail luzhengqi1828@126.com
\end{abstract}




\section{Introduction}

Atherosclerosis, a chronic multi-factorial vascular disease, has become a primary cause of death worldwide [1]. Atherosclerotic lesions, which primarily occur in large and medium-sized arteries, can be present throughout life and cause stroke or infarction due to ischemia in the brain, heart or extremities, and accumulating evidence has shown that injury and apoptosis in the vascular endothelium are critical events in the development and pathogenesis of atherosclerosis [2]. In certain pathological conditions, endothelial cells (ECs) apoptosis can increase the adhesion of platelets, facilitate infiltration of inflammatory cells and lipids into the intima and promote smooth muscle cells (SMCs) migration and proliferation, leading to atherogenesis [3]. Oxidized low-density lipoprotein cholesterol (oxLDL) is a well-established risk factor for atherothrombosis and exerts a plethora of effects to promote ECs apoptosis, plaque progression, and inflammatory interactions between monocytes and the underlying vessel wall [4]. Understanding the molecular mechanisms of how ox-LDL incites ECs apoptosis may uncover novel approaches to limit atherosclerosis.

MicroRNAs (miRNAs) are small non-coding RNAs that post-transcriptionally control protein translation through pairing with the 3'-untranslated region (3'-UTR) of the mRNA from their target genes [5]. MiRNAs have been found to play a significant role in vascular biology and atherosclerosis [6]. The activation of ECs promotes leukocyte recruitment from the blood into extravascular tissues and thus contributes to the pathogenesis of atherosclerosis. As one of the most highly expressed miRNAs in ECs, miR-126-3p interferes with this process by inhibiting the expression of VCAM-1 and impeding in vitro leukocyte adhesion to ECs [7]. Following their adhesion to the endothelium, inflammatory cells-mainly monocytes-can migrate into the intima, differentiate into macrophages and enhance the local inflammatory response. The expression of miR-155 increases progressively in lesional macrophages during atherogenesis and promotes inflammatory activation by targeting BCL6 [8]. Macrophages take up excessive modified lipoproteins via scavenger receptors, leading to the accumulation of intracellular cholesterol and triglycerides in the form of lipid droplets and the formation of "foam cells". In vitro studies have investigated the role of miRNAs in the regulation of ox-LDL uptake, showing that miR-125a-5p reduces the expression of the scavenger receptors CD68 and lectin-like ox-LDL receptor (LOX)-1 [9]. The dedifferentiation of VSMCs from a "contractile" to a "synthetic" phenotype, their proliferation and their migration from the media to the intima are crucial steps in the progression of atherosclerosis. Knowledge concerning the contribution of miRNAs to the regulation of the phenotypic switch of VSMCs has steadily grown in recent years. In particular, miR-143/-145 cluster thwarts proliferation and the acquisition of a synthetic phenotype [10]. Atherosclerotic plaque destabilization and rupture is the result of biologically active processes intricately regulated by miRNAs. Treatment with LNA anti-miR-24 in vivo is associated with a faster progression of atherosclerosis toward an unstable phenotype, characterized by decreased collagen content and increased macrophage infiltration [11]. Additionally, mounting evidence suggests that miRNAs orchestrate lipid metabolism and affect the development and progression of atherosclerosis. For example, antagonism of miR-33 in experimental animal models generally results in increased cholesterol efflux to ApoA1, thus increasing serum high-density lipoprotein (HDL) and decreasing cholesterol levels in peripheral tissues. The overall result is increased plaque stability, improved blood lipid profile, and inhibition of atherosclerosis progression [12]. However, whether miRNAs also participate in regulating atherosclerosis-associated ECs apoptosis remains largely unexplored.

MiRNA-142-3p (miR-142-3p), a miRNA that is well characterized in embryonic development and homeostasis, has been demonstrated to be an epigenetic regulator of cardiovascular diseases [13]. MiR-142-3p inhibits hypoxia/reoxygenation-induced apoptosis and fibrosis of cardiomyocytes, partly at least, by the direct inhibition of HMGB1 expression [14]. Exosomal miR-142-3p is increased during cardiac allograft rejection and compromises endothelial barrier function via down-regulation of RAB11FIP2 [15]. Chen et al. revealed that miR-142-3p is an important regulator of early cardiomyocyte differentiation [16]. 
Microarray analysis revealed that miR-142-3p is dramatically increased in human umbilical vein endothelia cells (HUVECs) treated with ox-LDL, which is generally considered as an inducer of ECs apoptosis [17]. The present study was designed to investigate the role of miR142-3p in ECs apoptosis in the setting of atherosclerosis and the underlying mechanisms.

\section{Materials and Methods}

\section{Cell culture and transfection}

Human aortic endothelial cells (HAECs) were obtained from ScienCell Research Laboratories (Carlsbad, CA, USA) and cultured in Endothelial Cell Medium (ECM, ScienCell, Carlsbad, CA) supplemented with endothelial cell growth factors (ScienCell, Carlsbad, CA), 5\% FBS (Invitrogen, Carlsbad, CA, USA) and 1\% penicillin/streptomycin (Invitrogen, Carlsbad, CA, USA). Cells were cultured in 6-well plates and exposed to ox-LDL $(100 \mu \mathrm{g} / \mathrm{ml})$ for $0,6,12$ and $24 \mathrm{~h}$.

Mimic and inhibitor oligonucleotides of miR-142-3p were synthesized by Ribo Bio (Guangzhou, China). MiRNA mimic negative control (NC mimic) and miRNA inhibitor negative control (NC inhibitor) (Ribo Bio, Guangzhou, China) are random sequence miRNA mimic molecule and inhibitor molecule that have been extensively tested in human cell lines and tissues and validated to not produce identifiable effects on known miRNA function. They are designed to be used as negative controls for experiments using miRNA mimics and inhibitors. The transfection was carried out using the lipid carrier lipofectamine 2000 (Invitrogen, Carlsbad, CA, USA) according to the manufacturer's instructions. Oligonucleotides (50 nM) prepared with lipid carrier were subjected to the transfection in a $2 \mathrm{ml}$ of Opti-MEM medium (Invitrogen, Carlsbad, CA, USA) for each well of the standard 6-well plates. The HAECs were incubated with the oligonucleotides/ lipofectamine complex for $24 \mathrm{~h}$ and then the medium was replaced by fresh medium with or without oxLDL $(100 \mu \mathrm{g} / \mathrm{ml}, 24 \mathrm{~h})$. In order to explore the involvement of Akt/endothelial nitric oxide synthase (eNOS) pathway in miR-142-3p suppression induced protection, HAECs were first pretreated with normal saline, LY294002 $(20 \mu \mathrm{m})$ or L-NAME $(100 \mu \mathrm{m})$ (Beyotime, Jiangsu, China) for $2 \mathrm{~h}$, and then were transfected with NC inhibitor or miR-142-3p inhibitor and further exposed to ox-LDL $(100 \mu \mathrm{g} / \mathrm{ml})$ for an additional $24 \mathrm{~h}$. After ox-LDL treatment, the cells were used for apoptosis measurement or protein/RNA extraction.

Rictor-specific siRNA and control scrambled siRNA (NC siRNA) were chemically synthesized from Ribo Bio (Guangzhou, China). HAECs were seeded in six-well plates at a concentration of $3 \times 10^{5}$ per well and grown overnight, and then the cells were transfected with Rictor siRNA at a final concentration of 50nM using lipofectamine 2000 reagent (Invitrogen, Carlsbad, CA, USA) according to the manufacturer's instructions. The Rictor-specific siRNA sequence was 5'-UGUAUCUGGACUAUGUCUGTT-3' and 5'-CAGACAUAGUCCAGAUACATT-3'. For rescue experiment, HAECs were co-transfected with miR-142-3p inhibitor ( $50 \mathrm{nM})$ and si-Rictor or NC siRNA. After that, HAECs were exposed to ox-LDL (100 $\mu \mathrm{g} / \mathrm{ml})$ for an additional $24 \mathrm{~h}$. Then cells were used for apoptosis measurement or protein extraction.

\section{Animal models}

ApoE $/$ mice on a C57BL/6 background were obtained from Beijing University of Medicine Laboratory. All experimental procedures were approved by the institutional animal care. Male 8-week-old ApoE $/$ mice were randomly divided into four groups (10 mice per group): miR-142-3p agomir negative control (AGNC), miR-142-3p agomir (AG), miR-142-3p antagomir negative control (AN-NC) and miR-142-3p antagomir (AN). All mice from different groups received tail vein injections of miRNA agomir/antagomir or their respective controls $(80 \mathrm{mg} / \mathrm{kg} / \mathrm{d})$ for 10 days after starting the high fat $/$ high cholesterol western diet $(15 \%$ fat wt $/ w t, 0.25 \%$ cholesterol wt/wt). After 8 weeks in the western diet, animals were sacrificed. The aortas were carefully excised, washed in cold PBS and freed of connective tissue. Four aortas randomly selected from each group were opened longitudinally and fixed in $4 \%$ formalin for $24 \mathrm{~h}$. Atherosclerotic lesions were identified as discrete and raised white areas stained with Sudan IV. The stained aorta was scanned with a digital camera and the total morphometric lesion area was evaluated with the NIH ImageJ software. Data were expressed as the percentage of atherosclerotic area relative to the whole aortic area. The residual aortas were divided into two parts. The thoraco aortas were embedded in paraffin. Serial sections of 4 $\mu \mathrm{m}$ were stained with hematoxylin/eosin (HE) for morphologic analysis. For the analysis of endothelial apoptosis, terminal transferase-mediated dUTP nick-end labeling (TUNEL) assay was performed according 


\section{Cellular Physiology Cell Physiol Biochem 2018;47:1589-1603 \begin{tabular}{l|l} 
and Biochemistry Published online: June 27, 2018 & $\begin{array}{l}\text { Do } 2018 \text { The Author(s). Published by S. Karger AG, Basel } \\
\text { www.karger.com/cpb }\end{array}$ \\
\hline
\end{tabular} \\ Qin et al.: Role of miR-142-3p in Endothelial Apoptosis}

to the specifications for in situ apoptosis detection kit. Micrographs were obtained using a Leica microscope (Leica DMI3000 B). To determine the apoptosis rate, 10 random fields from each section were quantified in a blinded manner. Three sections per group were used. The abdominal aortas were stored in liquid nitrogen. The expression of miR-142-3p was determined with qRT-PCR and the protein levels of Rictor and Akt were detected by western blot. All animal procedures were approved by the Sun Yat-sen University Animal Care and Use Committee.

\section{Ox-LDL preparation}

Human ox-LDL was isolated from fresh human plasma by sequential ultracentrifugation, as described previously [18].

\section{Measurement of apoptosis by Caspase-3 activity assay and flow cytometry}

The Caspase-3 activity was determined using colorimetric assay kits (Beyotime, Jiangsu, China) according to the instruction. Briefly, cells were collected and lysed using lysate buffer. After that, $40 \mu \mathrm{l}$ of the cell lysate (cytosolic extracts, $100 \mu \mathrm{g}$ ) was mixed with $50 \mu \mathrm{l}$ of reaction buffer and $10 \mu \mathrm{l}$ of Ac-DEVD- $\rho$ NA substrates (Beyotime, Jiangsu, China), and incubated at $37^{\circ} \mathrm{C}$ for $2 \mathrm{~h}$. After incubation, the chromophores were quantified spectrophotometrically at a wavelength of $405 \mathrm{~nm}$.

Cells were separated and washed three times with $\mathrm{PBS}\left(4^{\circ} \mathrm{C} \mathrm{pH} \mathrm{7.4)}\right.$ and centrifuged at $1000 \mathrm{rpm}$ for $5 \mathrm{~min}$. The binding buffer was diluted with pure water at a ratio of 1:4 and added $250 \mu \mathrm{l}$ to the cells. Cell suspension was stained using the Annexin V-FITC Apoptosis Detection Kit (Beyotime, Jiangsu, China) and the mixture was incubated for 15 min protecting from light at room temperature. The apoptosis was analyzed by flow cytometry and the results were analyzed with software LYSISII.

\section{Cell viability assay}

The cell viability of HAECs was determined by 3-(4, 5-dimethylthiazol-2-yl)-2, 5-diphenyltetrazolium bromide (MTT) assay. After treatment, $5 \mathrm{mg} / \mathrm{ml}$ MTT (MBI, USA) was added to each well. Subsequently, the cultures were incubated for an additional $4 \mathrm{~h}$ at $37{ }^{\circ} \mathrm{C}$. The supernatant was aspirated, and formazan crystals were dissolved in $150 \mu \mathrm{l}$ per well of dimethyl sulfoxide. The absorbance at $540 \mathrm{~nm}$ was measured with a microplate reader (Bio-tek, USA). Cell viability was calculated as follows: cell viability (\%) = optical density (OD) treatment/OD control (0 h) ×100\%.

\section{Cell proliferation assays}

The cell counting kit (CCK-8, Beyotime, Jiangsu, China) assay was used to determine cell proliferation. The HAECs $\left(1 \times 10^{4} / \mathrm{ml}\right)$ were seeded in a 96 well plate at $100 \mu \mathrm{l} /$ well and incubated overnight. HAECs were transfected with miR-142-3p mimic/inhibitor and then cultured with ox-LDL (100 $\mu \mathrm{g} / \mathrm{ml})$ for $24 \mathrm{~h} .10 \mu \mathrm{l}$ CCK8 solution was added to each well, according to the manufacturer's instructions. After $2 \mathrm{~h}$ incubation at $37^{\circ} \mathrm{C}$, the optical density value was measured at a wavelength of $450 \mathrm{~nm}$. The percentage inhibition of cell proliferation was determined by comparing the absorbance of treated with controls as follows: Inhibition $(\%)=[1-($ A of the experimental sample $/ \mathrm{A}$ of the control $)] \times 100 \%]$.

\section{MiRNA quantitative real-time PCR (qRT-PCR)}

Total RNA from cells was isolated using TRIzol reagent (Invitrogen, CA, USA) according to the manufacturer's protocol. To quantify the expression of miR-142-3p, we synthesized cDNA from 10 ng of RNA sample using the TaqMan MicroRNA Reverse Transcription Kit (Applied Biosystems, CA, USA). Quantitative PCR was performed with TaqMan MicroRNA Assays (Applied Biosystems, CA, USA) specific for miR-142-3p in a 7900HT RT-PCR machine (Applied Biosystems, CA, USA) according to the manufacturer's protocol. To normalize the expression level of miRNA, U6 RNA was used as an endogenous control.

\section{Western blot and mRNA qRT-PCR analysis}

HAECs and aortas were lysed and the protein extracts were denatured. The solubilized proteins (20 $\mu \mathrm{g}$ ) were subjected to electrophoresis, blotted to polyvinylidene difluoride membrane, and reacted with specific antibodies. Primary antibodies against Rictor (sc-81538), p-Akt (Ser473) (sc-514032), Akt (sc81434), p-eNOS (Ser 1177) (sc-81510), eNOS (sc-376751), GAPDH (sc-32233) and $\beta$-actin (sc-130065) were from Santa Cruz Biotechnology (Santa Cruz, CA, USA) and the secondary antibody was from KPL 


\begin{tabular}{|c|c|c|}
\hline Cellular Physiology & Cell Physiol Biochem 2018; & 47:1589-1603 \\
\hline and Riochemistry & $\begin{array}{l}\text { DOI: } 10.11159 / 000490932 \\
\text { Published online: June 27, } 2018\end{array}$ & $\begin{array}{l}\text { O } 2018 \text { The Author(s). Published by S. Karger AG, Basel } \\
\text { www.karger.com/cpb }\end{array}$ \\
\hline
\end{tabular}

(Gaithersburg, MD, USA). For mRNA analysis, cDNA was synthesized from $1 \mu \mathrm{g}$ of total RNA sample isolated through TRIzol reagent (Invitrogen, CA, USA) with RevertAid ${ }^{\mathrm{TM}}$ First Strand cDNA Synthesis kit (Fermentas, Lithuania) according to the standard protocol. $2 \mu$ cDNA was amplified by real-time polymerase chain reaction using the SYBR $®$ Premix Ex Taq ${ }^{\mathrm{TM}}$ II kits (TaKaRa, Dalian, China) with gene specific primers on a Applied Biosystems 7900HT RT-PCR system, according to the manufacturer's instructions.

\section{Luciferase assay}

Human Rictor 3'-UTR fragments containing potential binding sites for miR-142-3p were PCRamplified using human Rictor cDNA as the template. The PCR product was gel purified and subcloned into the SpeIHindIII site of pMIR-REPORT Luciferase vector (Ambion). We also generated a pMIR-Rictor-3'UTR mutant with three bases in the putative binding site. For luciferase assay, HAECs were co-transfected with $100 \mathrm{ng}$ of pMIR-Rictor-3'UTR or pMIR-Rictor-3'UTR mutant plasmid, and $50 \mathrm{nM}$ of miR-142-3p mimic or NC mimic combined with lipofectamine 2000 (Invitrogen, Carlsbad, CA, USA). After 48h incubation, the cells were washed and lysed. The relative luciferase activity was assayed using the Promega Dual-Luciferase reporter assay system. All the data were the average of at least three independent transfections.

\section{Statistical analysis}

Data are presented as mean \pm S.D. and evaluated by analysis of variance (ANOVA) or student $t$-test when appropriate. Significance was established at a level of $p<0.05$.

\section{Results}

MiR-142-3p is up-regulated in apoptotic HAECs induced by ox-LDL

After treatment of HAECs with $100 \mu \mathrm{g} / \mathrm{ml}$ ox-LDL for 0 to $24 \mathrm{~h}$, Caspase- 3 activity was increased in response to ox-LDL in a time-dependent manner. Flow cytometry analysis using Annexin V-FITC and propidium iodide (PI) double staining demonstrated that the percentage of apoptotic ECs was increased following ox-LDL treatment (Fig. 1A, 1B and 1C). The exposure of HAECs to ox-LDL at $100 \mu \mathrm{g} / \mathrm{ml}$ for $24 \mathrm{~h}$ resulted in a significant reduction of cell viability (Fig. 1D). With the increasing apoptotic rate, miR-142-3p was gradually increased in HAECs after ox-LDL incubation, and a more than threefold increase in the miR-142-3p amount was observed at $24 \mathrm{~h}$ (Fig. 1E).

Rictor is one of the target genes for miR-142-3p in HAECs

Function of miRNA relies on the inhibition of the target mRNA; therefore, we used the online bioinformatics prediction tools (TargetScan, miRanda and MIRDB) to identify the putative target genes of miR-142-3p. Among the consensus targets selected by three prediction programs, Rictor was of interest. Rictor knockdown attenuates cell cycle progression and enhances apoptosis in gastric cancer cells [19]. Moreover, miR-142-3p could suppress Rictor expression in YT cells [20]. MiR-142-3p was predicted to bind to the positions of 541-547 in Rictor 3'-UTR (Fig. 2C), and the binding energy between MiR-142-3p and Rictor was relatively low. Thus, Rictor may be a direct target of miR-142-3p in ECs. To investigate the effects of miR-142-3p on Rictor protein and mRNA expressions, miR-142-3p mimic or miR-142-3p inhibitor was transfected into HAECs. As shown in Fig. 2A, ox-LDL treatment decreased Rictor protein expression, which was inversely correlated with miR142-3p level. MiR-142-3p mimic dramatically reduced the protein level of Rictor and miR$142-3 p$ inhibitor increased the expression of Rictor protein. Although transfection of miR142-3p mimic or miR-142-3p inhibitor changed Rictor protein levels, transfection did not change Rictor mRNA expression (Fig. 2B). Therefore, miR-142-3p might directly regulate Rictor expression at the post-transcriptional level in HAECs.

To examine whether miR-142-3p directly binds the 3'UTR of Rictor mRNA, we constructed the luciferase reporter plasmid pMIR-ELK1-3'UTR containing the putative miR142-3p binding site of Rictor 3'UTR downstream of the luciferase open reading frame (Fig. 2C). When miR-142-3p mimic was co-transfected with pMIR-Rictor-3'UTR, the expression of 
Fig. 1. Apoptotic/necrotic effects and expression of miR-142-3p in HAECs exposed to ox-LDL for $0 \mathrm{~h}$, $6 \mathrm{~h}, 12 \mathrm{~h}$ and $24 \mathrm{~h}$. (A) Caspase-3 activity analysis of HAECs apoptosis. (B) Flow cytometric analysis of apoptosis and necrosis. The lower left quadrants of each panels show the viable cells, which exclude PI and are negative for AV binding (AV-/PI-). The lower right quadrants represent the apoptotic cells; AV positive and PI negative $(\mathrm{AV}+\mathrm{PI}-)$. The upper right quadrants contain the necrotic cells, positive for $\mathrm{AV}$ binding and for PI uptake $(\mathrm{AV}+\mathrm{PI}+)$. FL1-H: the fluorescence height of $\mathrm{AV}$; FL2-H: the fluorescence height of PI. (C) Comparison of the apoptotic and necrotic death rate of HAECs. (D) The viability of HAECs was measured using MTT assay. (E) Relative expression level of miR-142-3p in HAECs was analyzed using qRTPCR. Each bar represents the means \pm S.D. $(n=3),{ }^{*} \mathrm{p}<0.05$ versus 0 h group, ${ }^{* *} \mathrm{p}<0.01$ versus 0 h group.

Fig. 2. Experimental validation of Rictor as a target gene of miR-1423p. (A) HAECs were transfected with NC mimic, miR-142-3p mimic, NC inhibitor or miR-142-3p inhibitor and further exposed to oxLDL $(100 \mu \mathrm{g} / \mathrm{ml})$ for an additional $24 \mathrm{~h}$. Rictor protein was measured by western blot, and the GAPDH expression was used for protein level normalization. (B) Rictor mRNA was measured by qRT-PCR. (C) The putative target site of Rictor mRNA 3'UTR determined by computational predictions. The target sequence was cloned into pMIR-REPORT vector (pMIRRictor-3'UTR). pMIR-Rictor-3'UTR mutant was also generated with three bases mutation (indicated by italic characters) in the target site. (D) HAECs were transfected with pMIR-Rictor-3'UTR or pMIRRictor-3'UTR mutant together with
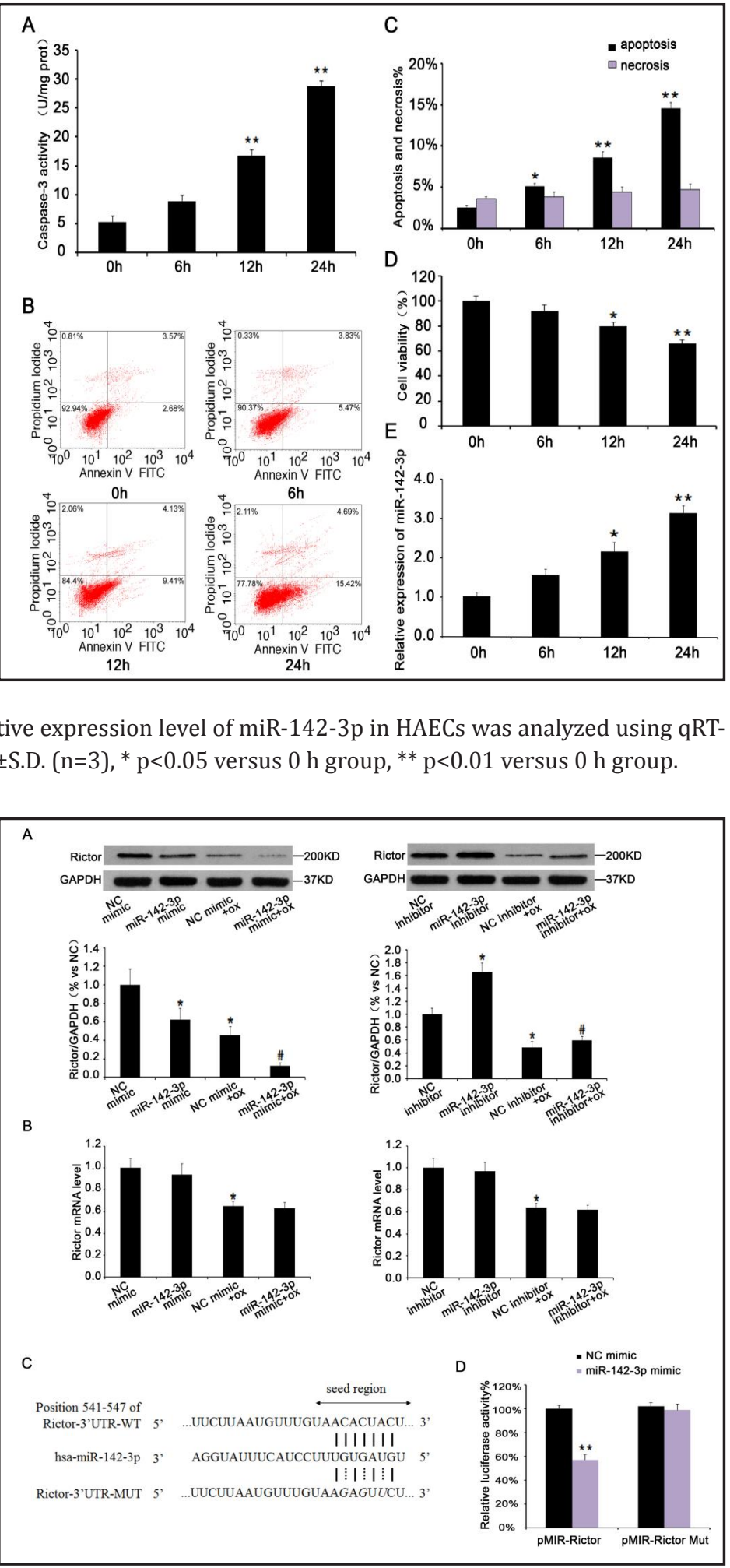

miR-142-3p mimic or NC mimic, and luciferase activity was measured and normalized to $\beta$-galactosidase expression levels. MiR-142-3p mimic reduced expression of luciferase containing a wild-type miR-142-3p binding site but not a mutant binding site. Values are means \pm S.D. $(n=3) .{ }^{*} \mathrm{p}<0.05$ compared with NC mimic/ inhibitor group, ${ }^{* *} \mathrm{p}<0.01$ compared with NC mimic/inhibitor group, $\# \mathrm{p}<0.05$ compared with NC mimic/ inhibitor +ox-LDL group. 
firefly luciferase was significantly decreased compared to the NC mimic co-transfected group (Fig. 2D). We also generated a pMIR-Rictor-3'UTR mutant with three bases mutation in the seed region of the putative binding sequence to investigate whether the down-regulation of firefly luciferase can be attributed to the mutation (Fig. 2C). Bases mutation blocked the inhibition of firefly luciferase induced by miR-142-3p mimic (Fig. 2D). These results strongly suggest a direct inhibitory effect of miR-142-3p on Rictor expression.

\section{Down-regulation of miR-142-3p suppresses ECs apoptosis}

The effect of miR-142-3p on ECs apoptosis was determined using Caspase-3 activity assay (Fig. 3A) and flow cytometry (Fig. 3B and 3C). The two methods showed that apoptotic rate of ECs was up-regulated in the presence of ox-LDL. Overexpression of miR-142-3p significantly enhanced apoptosis, whereas transfection with miR-142-3p inhibitor markedly diminished the ability of ox-LDL to induce apoptosis. Moreover, ox-LDL insult significantly inhibited HAECs survival and proliferation in our experimental condition. Overexpression of miR-142-3p after ox-LDL stimulation led to reduced survival and proliferation rate in HAECs, while knockdown of miR-142-3p elevated survival and proliferation of HAECs (Fig. 3D and Table 1).

Fig. 3. Influence of miR-142-3p on apoptosis and survival of HAECs induced by ox-LDL. HAECs were subjected to ox-LDL treatment after miR-142-3p mimic or inhibitor transfection. (A) The activity of Caspase-3 was determined by luminescent substrate assays. (B) Quantitative measurement of survival, apoptosis and necrosis by flow cytometry after AV/PI double stain. The lower left quadrants of each panels show the viable cells, which exclude PI and are negative for $\mathrm{AV}$ binding $(\mathrm{AV}-$ / PI-). The lower right quadrants represent the apoptotic cells; $\mathrm{AV}$ positive and PI negative $(\mathrm{AV}+/$ PI-). The upper right quadrants contain the necrotic cells, positive for $\mathrm{AV}$ binding and for PI uptake $(\mathrm{AV}+/ \mathrm{PI}+)$. FL1-H: the fluorescence height of AV; FL2-H: the fluorescence height of PI. (C) Comparison of the apoptotic and necrotic death rate of HAECs. (D) Comparison of the survival rate of HAECs. Values are means \pm S.D. $(n=3) .{ }^{*} p<0.05$ compared with NC mimic/inhibitor group, $* * \mathrm{p}<0.01$ compared with NC mimic/inhibitor group, \# p $<0.05$ compared with NC mimic/inhibitor+ox-LDL group, \#\# $\mathrm{p}<0.01$ compared with NC mimic/ inhibitor +ox-LDL group.

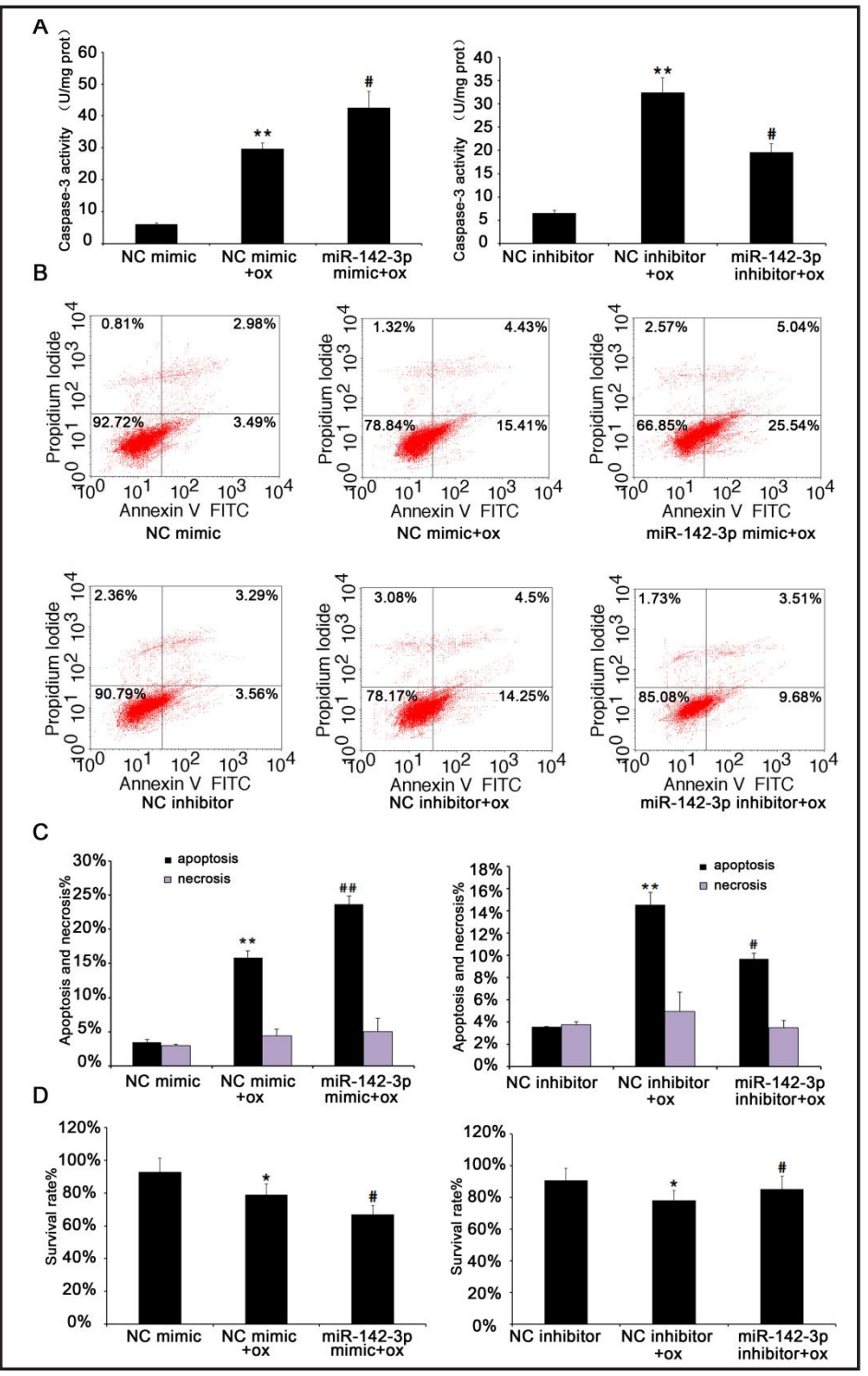


MiR-142-3p mediates endothelial apoptosis through targeting Rictor

To further clarify the role of Rictor in mediating the pro-apoptotic action of miR-142-3p in HAECs, we performed a rescue experiment. As shown in Fig. 4A, transfection of miR-142$3 p$ inhibitor up-regulated Rictor protein expression, whereas co-transfection with si-Rictor led to a significant decrease in the protein level of Rictor. Caspase- 3 activity assay and flow cytometry analysis showed that miR-142-3p inhibitor attenuated endothelial apoptosis elicited by ox-LDL, but repression of Rictor protein expression by siRNA abolished the beneficial effect of miR-142-3p inhibitor (Fig. 4B, 4C and 4D).

Involvement of Akt/eNOS signaling pathway in the miR-142-3p-mediated apoptosis of HAECs treated with ox- $L D L$

Rictor is an important component of mammalian target of rapamycin complex 2 (mTORC2) and the activation of the mTORC2 depends on the presence of the Rictor protein [21]. As the Akt/eNOS signaling pathway has been reported to be activated by mTORC2 and involved in modulating ECs apoptosis, we further elucidated whether Akt/eNOS signaling pathway was involved in the action of miR142-3p. As shown in Fig. 5A and 5B, oxLDL reduced the phosphorylation levels of Akt (Ser473) and eNOS (Ser1177) in HAECs after $24 \mathrm{~h}$ of incubation, but this tendency was partially reversed by knockdown of miR-142-3p. However, miR-142-3p mimic down-regulated the p-Akt and p-eNOS protein expression in ox-LDL-treated HAECs. While the transfection of miR-142-3p inhibitor increased the phosphorylation of Akt and eNOS, the selective Akt antagonist

Table 1. Anti-proliferation effect of miR-142-3p in HAECs. $\mathrm{A}_{450}$, absorption at $450 \mathrm{~nm}$. ${ }^{a}$ Percentage of decrease in proliferation rate compared with NC mimic/inhibitor. Values are means \pm S.D. $(n=3)$. ${ }^{* *} \mathrm{p}<0.01$ compared with NC mimic/inhibitor, \#p<0.05 compared with NC mimic/inhibitor +ox-LDL group

\begin{tabular}{lcc}
\hline & $\mathrm{A}_{450}$ & Inhibition ratio \\
\hline NC mimic & $0.97 \pm 0.03$ & - \\
NC mimic + ox & $0.71 \pm 0.05$ & $24.5 \%^{* *}$ \\
miR-142-3p mimic +ox & $0.55 \pm 0.02$ & $43.3 \%^{*}$ \\
NC inhibitor & $0.94 \pm 0.06$ & - \\
NC inhibitor +ox & $0.69 \pm 0.03$ & $26.6 \%^{* *}$ \\
miR-142-3p inhibitor+ox & $0.83 \pm 0.04$ & $11.7 \%^{\#}$ \\
\hline
\end{tabular}

Fig. 4. MiR-142-3p modulated HAECs apoptosis through Rictor. (A) Rictor protein decreased by transfection of si-Rictor in HAECs. Rictor protein level was measured by Western blotting. Downregulation of Rictor by si-Rictor blocked the ability of miR-142-3p inhibitor to suppress apoptosis in ox-LDL treated HAECs. The apoptosis was measured by Caspase-3 activity assay (B) and flow cytometry after AV/PI double stain (C and D). Values are means \pm S.D. $(\mathrm{n}=3),{ }^{*} \mathrm{p}<0.05, * *$ $\mathrm{p}<0.01$.

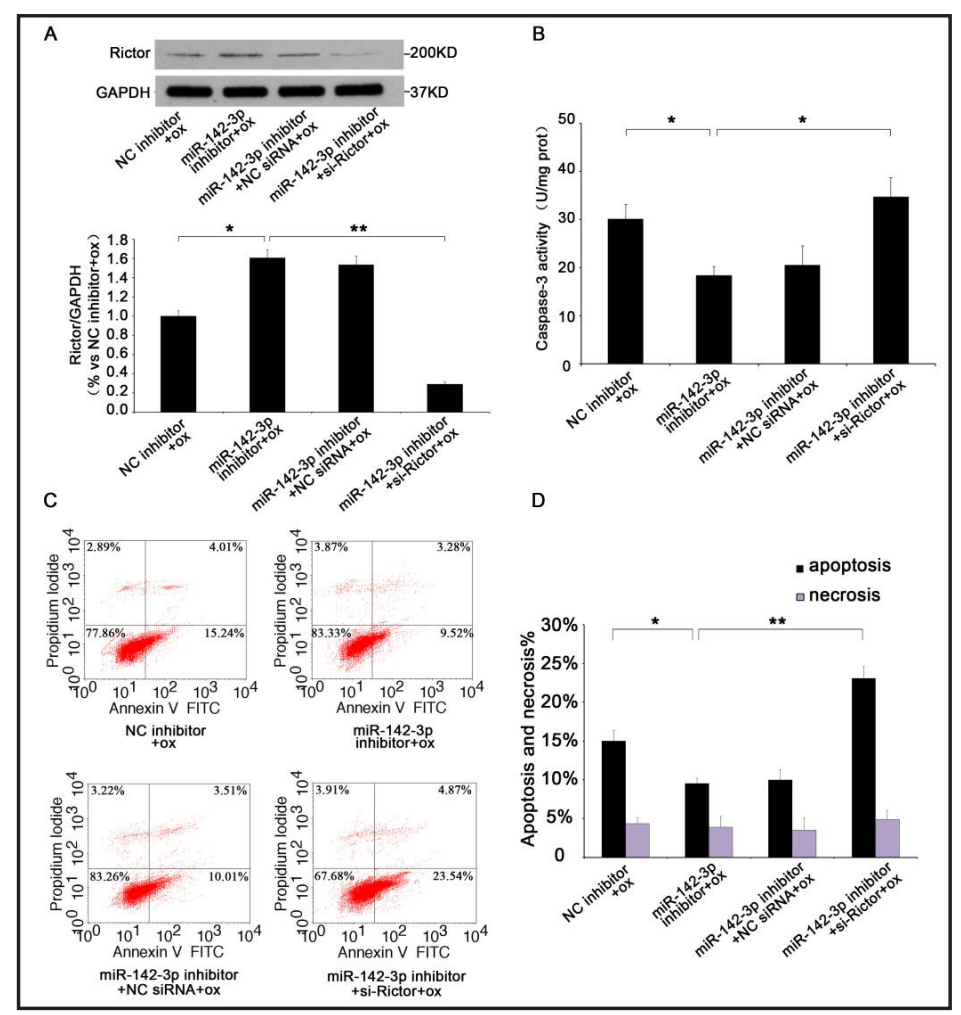


Fig. 5. Down-regulation of miR142-3p reduced endothelial apoptosis via Akt/eNOS signaling pathway. MiR-142-3p regulated the phosphorylation of Akt (A) and eNOS (B). HAECs were exposed to ox-LDL $(100 \mu \mathrm{g} / \mathrm{ml}, 24 \mathrm{~h})$ after miR-142-3p mimic or inhibitor transfection. Total lysate from each sample was subjected to western blot analysis using specific antibodies to Akt at Ser-473 and eNOS at Ser-1177 (top panel). The intensity of protein bands was quantified and was shown as relative expression level after normalized by $\beta$-actin (bottom panel). HAECs were pretreated with normal saline, LY294002 (20 $\mu \mathrm{m})$ or L-NAME $(100 \mu \mathrm{m})$ for $2 \mathrm{~h}$, and then were transfected with NC inhibitor or miR-142-3p inhibitor and further exposed to ox-LDL $(100 \mu \mathrm{g} / \mathrm{ml})$ for an additional 24 h. The expression levels of Akt,

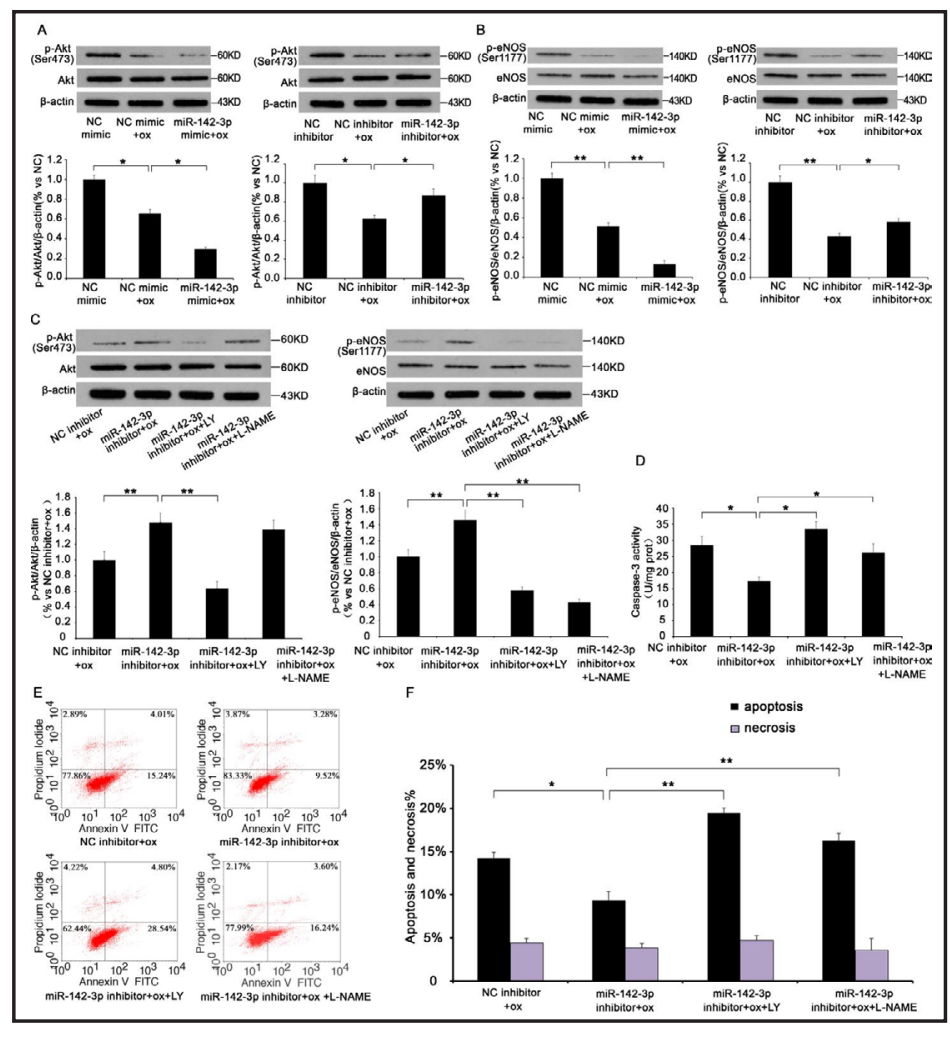
pS473-Akt, eNOS and pS1177-

eNOS were measured by western blot analysis (C). The apoptosis was detected by Caspase-3 activity assay (D) and flow cytometry after AV/PI double stain (E and F). Values are means \pm S.D. $(n=3),{ }^{*} p<0.05,{ }^{* *} \mathrm{p}<0.01$.

LY294002 markedly prevented the miR-142-3p inhibitor-induced phosphorylation of Akt and eNOS. The eNOS inhibitor L-NAME only reduced eNOS phosphorylation, with no effect on p-Akt expression after ox-LDL and miR-142-3p inhibitor treatment (Fig. 5C). Furthermore, inhibition of miR-142-3p markedly ameliorated ECs apoptosis. When the Akt/ eNOS signaling pathway was blocked by LY294002 or L-NAME, miR-142-3p inhibitor failed to protect cells against ox-LDL-induced apoptosis (Fig. 5D, 5E and 5F). Altogether, these data reveal that miR-142-3p inhibitor exerts its anti-apoptotic effect through activating the Akt/ eNOS signaling pathway.

MiR-142-3p promotes endothelial apoptosis and development of aortic atherosclerosis in ApoE ${ }^{-/}$mice

To determine whether endothelial apoptosis was regulated by miR-142-3p in vivo, ApoE $\%$ mice were fed with a high-fat diet (HFD) and injected intravenously with miR-142$3 p$ agomir (AG) or antagomir (AN) or control miRNA oligonucleotides (AG-NC/AN-NC). First we measured the expression of miR-142-3p in the aorta of mice. The expression of miR-142$3 p$ in the aorta was increased in AG treated mice. On the other hand, the expression level of miR-142-3p was decreased by more than $50 \%$ in AN treated mice compared with those of mice receiving AN-NC (Fig. 6A). These data suggest that injection of miR-142-3p agomir and antagomir can significantly alter miR-142-3p level in the aorta of mice. TUNEL staining was then performed to assess endothelial apoptosis in the aorta of $\mathrm{ApoE}^{-/-}$mice. Results showed that AG significantly increased the percentage of TUNEL-positive cells compared with AG-NC. Administration of AN significantly reduced the percentage of TUNEL-positive cells (Fig. 6B). Moreover, we investigated the role of miR-142-3p in the development of atherosclerosis in $\mathrm{ApoE} /$ mice fed with HFD. The atherosclerotic lesion area was examined by an en face analysis of the total aorta and the cross-sections of the thoraco aorta. The en 
Fig. 6. Effects of miR-142-3p on endothelial apoptosis and atherosclerotic lesion area in ApoE $^{-/}$mice. Male 8-week-old $\mathrm{ApoE}^{-/-}$mice were given a tail vein injection with miR-142-3p agomir negative control (AG$\mathrm{NC}$ ), miR-142-3p agomir (AG), miR-142-3p antagomir negative control (AN-NC) or miR-142-3p antagomir (AN) $(80 \mathrm{mg} / \mathrm{kg} / \mathrm{d})$ for 10 days and remained in high fat/high cholesterol Western diet until after 8 weeks. (A) Relative expression level of miR-142-3p in the aorta was analyzed using qRT-PCR. Values are means \pm S.D. $(\mathrm{n}=6)$. (B) Apoptotic cells in the aortic endothelium were detected by TUNEL staining. Representative images of TUNEL assay in AG-NC,

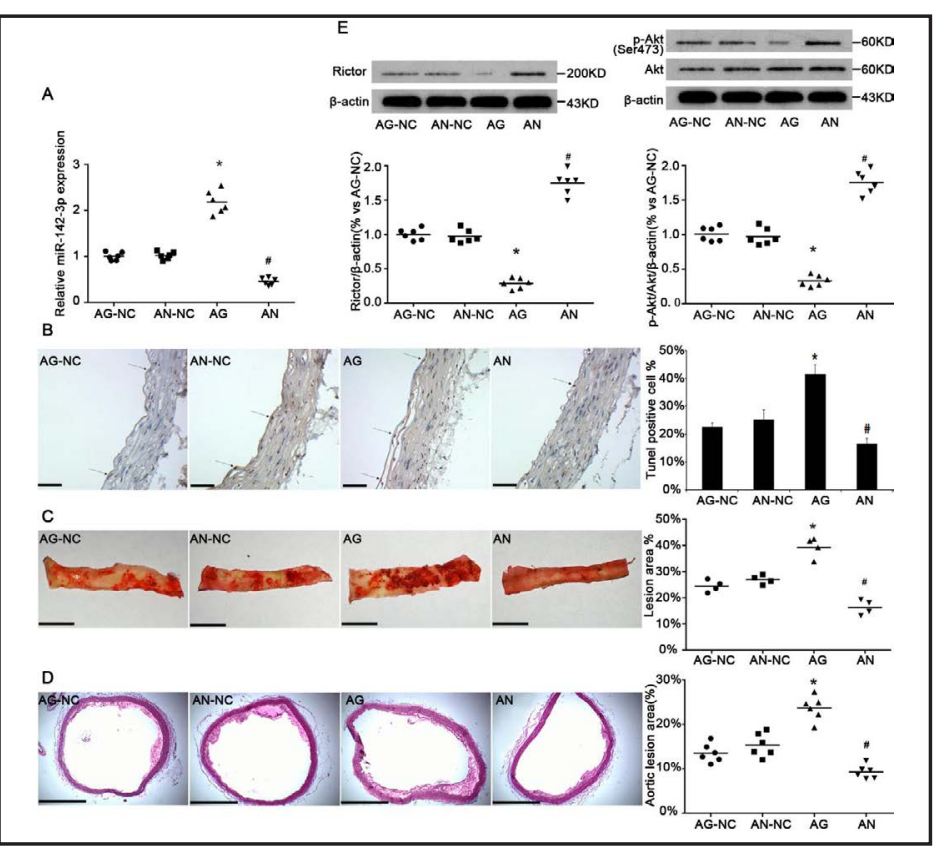
AG, AN-NC and AN groups (left). Nuclei of normal cells are blue, and nuclei of apoptosis cells are brown. Black arrows represent the positive staining of TUNEL. Quantitative plot of TUNEL positive cells in AGNC, AG, AN-NC and AN groups (right). Apoptosis rate was determined by the ratio of apoptotic nuclei to total nuclei. Values are means \pm S.D. Bar $=80 \mu \mathrm{m},(n=6)$. (C) Representative images and the quantification of atherosclerotic lesion area in the en face analysis of the aorta with Sudan IV staining in ApoE $\mathrm{E}^{-/-} \mathrm{mice}^{-}$ Values are means \pm S.D. Bar $=3 \mathrm{~mm},(\mathrm{n}=4)$. (D) Representative microscopic images and quantification of atherosclerotic plaque area in cross-sections of thoraco aorta with hematoxylin-eosin staining in $\mathrm{ApoE}^{-/}$ mice. Values are means \pm S.D. Bar $=500 \mu \mathrm{m},(n=6)$. (E) The expression levels of Rictor, Akt and pS473-Akt in the aorta of $\mathrm{ApoE}^{-/}$mice were determined using western blot. Values are means \pm S.D. $(\mathrm{n}=6),{ }^{*} \mathrm{p}<0.05$ compared with AG-NC group, \#p<0.05 compared with AN-NC group.

face analysis of the total aorta showed that atherosclerotic lesions in the aorta of $\mathrm{ApoE}^{\%}$ mice were significantly increased in AG group compared with the AG-NC group. Conversely, AN treated mice had a statistically significant reduction in atherosclerotic plaque formation in comparison to AN-NC (Fig. 6C). We then examined atherosclerotic plaque development by thoraco aorta HE stained lesions, and found that the plaque area in AG-treated mice was greater and more severe than that in mice treated with AG-NC. On the other hand, plaques in AN-treated mice were markedly reduced compared with plaques in the AN-NC mice (Fig. 6D). Finally, we investigated the effects of miR-142-3p on Rictor expression and phosphorylation of Akt in vivo. The isolated aorta from each group was homogenized for the determination of Rictor expression and Akt phosphorylation by western blot (Fig. 6E). The expression of Rictor in the aorta in ApoE $/$ mice was significantly reduced in AG group, but increased in AN group, compared with those in mice injected with the negative control. The level of Akt phosphorylation on serine 473 was significantly lower in AG group compared with control mice, and AN treatment resulted in an increase of aortic Akt phosphorylation. Together, these results indicate that miR-142-3p promotes endothelial apoptosis in vivo and the development of atherosclerosis probably through suppression of Rictor expression and Akt phosphorylation.

\section{Discussion}

Atherosclerosis is an intricate disease of medium and large-sized arteries. Importantly, the first step in the pathogenesis of atherosclerosis appears to be vascular injury, and 
endothelial apoptosis plays a vital role in endothelial dysfunction and atherosclerosis lesion formation [22]. Since ox-LDL is a major risk factor for the onset and development of atherosclerosis [23], the present study used ox-LDL-treated HAECs as an experimental model to identify the specific miRNAs associated with endothelial apoptosis in atherosclerosis.

During the past few years, miRNAs have emerged as key regulators for endothelial biology and dysfunction [6]. Deregulation of miRNA expression has been proved to be associated with endothelial angiogenesis, injury, inflammation and senescence. The mechanistic studies revealed that miR-93-5p can promote angiogenic process through inhibiting EPLIN expression in ECs [24]. It has been demonstrated that miR-126 overexpression activates PI3K/Akt/mTOR pathway, thereby restoring the autophagic flux and alleviating ox-LDLinduced ECs injury [25]. MiR-20b is showed to target RBL1 in the modulation of premature senescence in ECs induced by chronic exposure to TNF- $\alpha$ [26]. Furthermore, aberrantly expressed miRNAs have recently been reported to play a role in the regulation of ECs survival/death in the setting of atherosclerosis. For example, up-regulation of miR-876 induces ECs apoptosis by suppressing anti-apoptotic protein Bcl-xl in the development of atherosclerosis [27]. MiR-351, up-regulated in the serum and ECs of the atherosclerotic mice, can attenuate the survival of ECs and suppress angiogenesis through targeting STAT3 [28]. Thus, the identification of miRNAs and their targets may cast new light on the therapeutic strategies to endothelial dysfunction and atherosclerosis. The present study demonstrated for the first time that miR-142-3p exerted an effect on modulating endothelial apoptosis. Specifically, overexpression of miR-142-3p significantly enhanced endothelial apoptosis whereas inhibition of miR-142-3p could partly alleviate apoptotic cell death in vitro and in vivo. The study of the mechanism underlying this effect revealed that miR-142-3p promoted ECs apoptosis by suppressing the downstream target Rictor and the Akt/eNOS signaling pathway. Overall, our study provided evidence to suggest that miR-142-3p may be a novel target for the prevention and treatment of atherosclerosis.

MiR-142-3p, localized on chromosome 17q22, is reported to be down-regulated and plays a pro-apoptotic role in various tumors [13]. For example, it has been revealed that overexpression of miR-142-3p improves drug sensitivity of acute myelogenous leukemia (AML) cells by inhibiting cell viability and promoting apoptosis [29]. Zhang et al. indicated that miR-142-3p inhibits non-small cell lung carcinoma (NSCLC) cell proliferation and induces cell apoptosis via targeting HMGB1 [30]. In addition, it has been shown that miR$142-3 p$ is a key regulator of cardiomyocytes apoptosis and fibrosis induced by hypoxia/ reoxygenation [14], therefore serving as a candidates for myocardial injury therapeutic strategy. A recent study done by Bao et al. demonstrated that platelet-derived miR-142-3p is delivered into ECs via platelet-derived microparticles (PMPs) and induces ECs apoptosis in hypertension through modulating the expression of target molecule BCL2L1 [31]. Consistent with these findings, we found that miR-142-3p was an essential mediator for ECs apoptosis both in vitro and in vivo. MiR-142-3p was up-regulated in the apoptotic HAECs elicited by ox-LDL. Over-expression of miR-142-3p promoted ECs apoptosis, whereas depletion of miR142-3p suppressed ox-LDL-elicited apoptosis in HAECs. Previous research has shown that ox-LDL may induce apoptosis, necrosis or proliferation of cultured ECs depending on the concentration and exposure time [32]. Ox-LDL at concentration lower than $10 \mu \mathrm{g} / \mathrm{ml}$ could promote proliferation, at concentration higher than $50 \mu \mathrm{g} / \mathrm{ml}$ could induce apoptosis and at higher than $250 \mu \mathrm{g} / \mathrm{ml}$ could induce necrosis in HUVECs [18]. Under our experimental conditions, treatment with $100 \mu \mathrm{g} / \mathrm{ml}$ ox-LDL for $24 \mathrm{~h}$ significantly inhibited the survival and proliferation in HAECs, which could be exacerbated by miR-142-3p mimic and alleviated by its inhibitor. Incubation of HAECs with $100 \mu \mathrm{g} / \mathrm{ml}$ ox-LDL for $0-24 \mathrm{~h}$ did not significantly increase the necrotic percentage. Transfection of miR-142-3p inhibitor slightly decreased necrosis in HAECs, but the difference had no statistical significance. To further explore the influence of miR-142-3p on endothelial apoptosis in vivo, male ApoE KO mice were applied and transducted with AG or AN through tail vein injection. As a result, there was a marked increase in endothelial apoptosis in mice treated with AG, as visible by TUNEL staining. In contrast, knockdown of miR-142-3p by AN significantly attenuated endothelial apoptosis. 
Additionally, treatment with AG caused a significant increase in lesion size in aortic wall. Conversely, the atherogenesis was abrogated by miR-142-3p suppression. These results demonstrated the pro-atherosclerotic effect of miR-142-3p in vivo.

The mammalian target of rapamycin (mTOR) pathway is a key regulator of cell growth and proliferation, and increasing evidence suggests that its dysregulation is associated with human diseases, including cancer, diabetes and cardiovascular disease. Recent work identified two structurally and functionally distinct mTOR-containing multiprotein complexes. The first complex, mTORC1, harbors raptor specifically activates protein synthesis via S6 kinase (S6K). The second complex, mTORC2, is associated with Rictor and phosphorylates Akt on Ser473. mTORC2 phosphorylates and activates Akt/protein kinase B, which promotes signaling pathways that ensure cell survival and induce cell proliferation [33]. Rictor is an important component of mTORC2 and the activation of the mTORC2 depends on the presence of the Rictor protein. Rictor is necessary for Akt phosphorylation on Ser473 and that a reduction in Rictor expression inhibits an Akt effector [34]. Upon activation Akt mediates pro-survival and anti-apoptosis in part via phosphorylating downstream target proteins including eNOS, BAD, Caspase-9, Fox1, Fox3a, YAP and MDM2 [35]. Among these target proteins, one of the most important one is eNOS. It is widely known that dysfunction of the eNOS activity leads to the reduction of NO bioavailability, which contributes to atherosclerosis [36]. The Rictor/Akt/eNOS pathway has been shown to play a pivotal role in regulating ECs apoptosis and dysfunction. Knockdown of Rictor inhibited activation of Akt and reduced ECs proliferation, migration, neovascularization $[37,38]$ and promoted endothelial apoptosis $[37,39]$, inflammation [39] and senescence [40]. To the contrary, fibroblast growth factor (FGF) [38], vascular endothelial growth factor (VEGF) [41] and 14, 15-epoxyeicosatrienoic acid [40] could provoke the expression of Rictor and phosphorylation of Akt, suppressing apoptosis and senescence of ECs. Ox-LDL induced apoptosis and oxidative stress in HAECs through inhibiting Akt/eNOS signaling pathway [42]. In the current study, we found that overexpression of miR-142-3p decreased Rictor protein expression and Akt phosphorylation, whereas knockdown of miR-142-3p enhanced the expression of Rictor and activation of Akt both in vitro and in vivo. Further luciferase reporter assay analysis revealed that Rictor gene is one of the direct targets of miR-142-3p in ECs. With Rictor down-regulation, miR-142$3 p$ inhibitor lost its ability to suppress apoptosis. Ox-LDL inhibited Akt/eNOS activity and endothelial apoptosis correspondingly increased. While miR-142-3p inhibitor enhanced activity of Akt and eNOS, application of LY294002 and L-NAME reduced the phosphorylation of Akt and eNOS as well as abolished the anti-apoptotic effect of miR-142-3p inhibitor. These results suggest that down-regulation of miR-142-3p can ameliorate ECs apoptosis by activating the Rictor/Akt/eNOS signaling pathway.

Our study has several limitations that warrant further investigation. A major limitation of this study is that we have not examined the immune-related side-effects. Atherosclerosis is a chronic inflammatory disease of the arterial wall characterized by innate and adaptive immune system involvement. A key component of atherosclerotic plaque inflammation is the persistence of different immune cell types including monocytes, macrophages, dendritic cells, T cells, mast cells, etc [43]. Over the years, miR-142-3p has gained considerable attention for its quintessential role in regulating the function of immune cells [44]. The study done by Lagrange et al. identified the contribution of miR-142-3p to CSF1-induced differentiation of human monocytes into macrophages and demonstrated that this miRNA is part of a molecular circuitry involved the transcription factor Egr2 [45]. MiR-142-3p plays a critical role in modulating age-associated dysfunction of macrophages and LPS-induced dendritic cells responses and mortality via targeting IL-6 [46, 47]. The expression of miR$142-3 \mathrm{p}$ is down-regulated in $\mathrm{CD} 4^{+} \mathrm{T}$ cells from patients with arteriosclerosis obliterans. The down-regulation of miR-142-3p could increase the migration of CD $4^{+} \mathrm{T}$ cells to the vascular walls by regulation of actin cytoskeleton via its target genes, RAC1 and ROCK2 [48]. In the current study, injection of miR-142-3p agomir and antagomir in vivo may also influence miR$142-3 p$ expression and function of these immune cells, which may affect the development and progression of atherosclerosis. Secondly, it has been demonstrated that miR-142-3p is

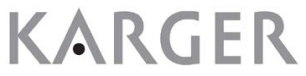


induced upon TGF $\beta$ signaling in VSMCs, acting as a critical regulator of the TGF $\beta$-mediated contractile phenotype of VSMCs by targeting DOCK6. The phenotypic switching of VSMCs has long been considered of fundamental importance to atherosclerosis [49]. Thus, VSMCs may also be involved in the effect of miR-142-3p on development of atherosclerosis. Moreover, thousands of potential target genes of miR-142-3p were predicted by database, and the participation of other target genes such as IL-6, RAC1 and DOCK6 in the process requires further study. Finally, because we did not recruit a sufficient number of patients with atherosclerosis, the precise effect of miR-142-3p on atherosclerosis remains to be further validated in individuals.

In conclusion, we provide compelling evidence that down-regulation of miR-142-3p could alleviate ECs apoptosis and development of atherosclerosis via up-regulating Rictor expression and activating Akt/eNOS signaling pathway. This study provides a new target for the treatment of endothelial dysfunction and atherosclerosis at the gene level.

\section{Acknowledgements}

This study was supported by the grant of the National Natural Science Foundation of China (No. 81701167), the Natural Science Foundation of Guangdong Province, China (2017A030310360), and the Medical Scientific Research Foundation of Guangdong Province, China (No. A2016059).

\section{Disclosure Statement}

The authors declare that they have no conflict of interests.

\section{References}

1 Benjamin EJ, Blaha MJ, Chiuve SE, Cushman M, Das SR, Deo R, de Ferranti SD, Floyd J, Fornage M, Gillespie C, Isasi CR, Jimenez MC, Jordan LC, Judd SE, Lackland D, Lichtman JH, Lisabeth L, Liu S, Longenecker CT, Mackey RH, Matsushita K, Mozaffarian D, Mussolino ME, Nasir K, Neumar RW, Palaniappan L, Pandey DK, Thiagarajan RR, Reeves MJ, Ritchey M, Rodriguez CJ, Roth GA, Rosamond WD, Sasson C, Towfighi A, Tsao CW, Turner MB, Virani SS, Voeks JH, Willey JZ, Wilkins JT, Wu JH, Alger HM, Wong SS, Muntner P, American Heart Association Statistics C, Stroke Statistics S: Heart Disease and Stroke Statistics-2017 Update: A Report From the American Heart Association. Circulation 2017;135:e146-e603.

-2 Bai X, Wang X, Xu Q: Endothelial damage and stem cell repair in atherosclerosis. Vascul Pharmacol 2010;52:224-229.

3 Choy JC, Granville DJ, Hunt DW, McManus BM: Endothelial cell apoptosis: biochemical characteristics and potential implications for atherosclerosis. J Mol Cell Cardiol 2001;33:1673-1690.

4 Steinberg D, Witztum JL: Oxidized low-density lipoprotein and atherosclerosis. Arterioscler Thromb Vasc Biol 2010;30:2311-2316.

5 Bartel DP: MicroRNAs: genomics, biogenesis, mechanism, and function. Cell 2004;116:281-297.

6 Santulli G: MicroRNAs and Endothelial (Dys) Function. J Cell Physiol 2016;231:1638-1644.

7 Harris TA, Yamakuchi M, Ferlito M, Mendell JT, Lowenstein CJ: MicroRNA-126 regulates endothelial expression of vascular cell adhesion molecule 1. Proc Natl Acad Sci U S A 2008;105:1516-1521.

8 Nazari-Jahantigh M, Wei Y, Noels H, Akhtar S, Zhou Z, Koenen RR, Heyll K, Gremse F, Kiessling F, Grommes J, Weber C, Schober A: MicroRNA-155 promotes atherosclerosis by repressing Bcl6 in macrophages. J Clin Invest 2012;122:4190-4202.

-9 Chen T, Huang Z, Wang L, Wang Y, Wu F, Meng S, Wang C: MicroRNA-125a-5p partly regulates the inflammatory response, lipid uptake, and ORP9 expression in oxLDL-stimulated monocyte/macrophages. Cardiovasc Res 2009;83:131-139. 


\section{Cellular Physiology Cell Physiol Biochem 2018;47:1589-1603 and Biochemistry Published online: June 27, $2018 \quad \begin{aligned} & \text { DOI: 10.1159/000490932 } 2018 \text { The Author(s). Published by S. Karger AG, Basel } \\ & \text { www.karger.com/cpb }\end{aligned}$ \\ Qin et al.: Role of miR-142-3p in Endothelial Apoptosis}

10 Cordes KR, Sheehy NT, White MP, Berry EC, Morton SU, Muth AN, Lee TH, Miano JM, Ivey KN, Srivastava D: miR-145 and miR-143 regulate smooth muscle cell fate and plasticity. Nature 2009;460:705-710.

11 Di Gregoli K, Jenkins N, Salter R, White S, Newby AC, Johnson JL: MicroRNA-24 regulates macrophage behavior and retards atherosclerosis. Arterioscler Thromb Vasc Biol 2014;34:1990-2000.

12 Novak J, Olejnickova V, Tkacova N, Santulli G: Mechanistic Role of MicroRNAs in Coupling Lipid Metabolism and Atherosclerosis. Adv Exp Med Biol 2015;887:79-100.

13 Shrestha A, Mukhametshina RT, Taghizadeh S, Vasquez-Pacheco E, Cabrera-Fuentes H, Rizvanov A, Mari B, Carraro G, Bellusci S: MicroRNA-142 is a multifaceted regulator in organogenesis, homeostasis, and disease. Dev Dyn 2017;246:285-290.

14 Wang Y, Ouyang M, Wang Q, Jian Z: MicroRNA-142-3p inhibits hypoxia/reoxygenationinduced apoptosis and fibrosis of cardiomyocytes by targeting high mobility group box 1. Int J Mol Med 2016;38:1377-1386.

15 Sukma Dewi I, Celik S, Karlsson A, Hollander Z, Lam K, McManus JW, Tebbutt S, Ng R, Keown P, McMaster R, McManus B, Ohman J, Gidlof O: Exosomal miR-142-3p is increased during cardiac allograft rejection and augments vascular permeability through down-regulation of endothelial RAB11FIP2 expression. Cardiovasc Res 2017;113:440-452.

16 Chen ZY, Chen F, Cao N, Zhou ZW, Yang HT: miR-142-3p Contributes to Early Cardiac Fate Decision of Embryonic Stem Cells. Stem Cells Int 2017;2017:1769298.

17 Qin B, Xiao B, Liang D, Xia J, Li Y, Yang H: MicroRNAs expression in ox-LDL treated HUVECs: MiR-365 modulates apoptosis and Bcl-2 expression. Biochem Biophys Res Commun 2011;410:127-133.

18 Chen XP, Xun KL, Wu Q, Zhang TT, Shi JS, Du GH: Oxidized low density lipoprotein receptor-1 mediates oxidized low density lipoprotein-induced apoptosis in human umbilical vein endothelial cells: role of reactive oxygen species. Vascul Pharmacol 2007;47:1-9.

19 Bian YH, Xu J, Zhao WY, Zhang ZZ, Tu L, Cao H, Zhang ZG: Targeting mTORC2 component rictor inhibits cell proliferation and promotes apoptosis in gastric cancer. Am J Transl Res 2017;9:4317-4330.

20 Chen HH, Huang WT, Yang LW, Lin CW: The PTEN-AKT-mTOR/RICTOR Pathway in Nasal Natural Killer Cell Lymphoma Is Activated by miR-494-3p via PTEN But Inhibited by miR-142-3p via RICTOR. Am J Pathol 2015;185:1487-1499.

-21 Perl A: Activation of mTOR (mechanistic target of rapamycin) in rheumatic diseases. Nat Rev Rheumatol 2016;12:169-182.

22 Alvarez RJ, Gips SJ, Moldovan N, Wilhide CC, Milliken EE, Hoang AT, Hruban RH, Silverman HS, Dang CV, Goldschmidt-Clermont PJ: 17beta-estradiol inhibits apoptosis of endothelial cells. Biochem Biophys Res Commun 1997;237:372-381.

23 Zhou Z, Subramanian P, Sevilmis G, Globke B, Soehnlein O, Karshovska E, Megens R, Heyll K, Chun J, Saulnier-Blache JS, Reinholz M, van Zandvoort M, Weber C, Schober A: Lipoprotein-derived lysophosphatidic acid promotes atherosclerosis by releasing CXCL1 from the endothelium. Cell Metab 2011;13:592-600.

24 Liang L, Zhao L, Zan Y, Zhu Q, Ren J, Zhao X: MiR-93-5p enhances growth and angiogenesis capacity of HUVECs by down-regulating EPLIN. Oncotarget 2017;8:107033-107043.

-25 Tang F, Yang TL: MicroRNA-126 alleviates endothelial cells injury in atherosclerosis by restoring autophagic flux via inhibiting of PI3K/Akt/mTOR pathway. Biochem Biophys Res Commun 2018;495:14821489.

26 Wong PF, Jamal J, Tong KL, Khor ES, Yeap CE, Jong HL, Lee ST, Mustafa MR, Abubakar S: Deregulation of hsa-miR-20b expression in TNF-alpha-induced premature senescence of human pulmonary microvascular endothelial cells. Microvasc Res 2017;114:26-33.

27 Xu K, Liu P, Zhao Y: Upregulation of microRNA-876 Induces Endothelial Cell Apoptosis by Suppressing Bcl$\mathrm{Xl}$ in Development of Atherosclerosis. Cell Physiol Biochem 2017;42:1540-1549.

28 Zhang Y, Liu Y, Zhang H, Wang M, Zhang J: Mmu-miR-351 attenuates the survival of cardiac arterial endothelial cells through targeting STAT3 in the atherosclerotic mice. Biochem Biophys Res Commun 2015;468:300-305.

29 Zhang Y, Liu Y, Xu X: Upregulation of miR-142-3p Improves Drug Sensitivity of Acute Myelogenous Leukemia through Reducing P-Glycoprotein and Repressing Autophagy by Targeting HMGB1 Transl Oncol 2017;10:410-418. 


\section{Cellular Physiology Cell Physiol Biochem 2018;47:1589-1603 \begin{tabular}{l|l} 
DOI: 10.1159/000490932 & Ond Biochemistry 2018 The Author(s). Published by S. Karger AG, Basel \\
Published online: June 27, 2018 & $\begin{array}{l}\text { wwwarger.com/cpb } \\
\text { Qn }\end{array}$
\end{tabular} \\ Qin et al.: Role of miR-142-3p in Endothelial Apoptosis}

30 Xiao P, Liu WL: MiR-142-3p functions as a potential tumor suppressor directly targeting HMGB1 in nonsmall-cell lung carcinoma. Int J Clin Exp Pathol 2015;8:10800-10807.

-31 Bao H, Yao QP, Huang K, Chen XH, Han Y, Jiang ZL, Gao LZ, Qi YX: Platelet-derived miR-142-3p induces apoptosis of endothelial cells in hypertension. Cell Mol Biol (Noisy-le-grand) 2017;63:3-9.

-32 Zhang Y, Xie Y, You S, Han Q, Cao Y, Zhang X, Xiao G, Chen R, Liu C: Autophagy and Apoptosis in the Response of Human Vascular Endothelial Cells to Oxidized Low-Density Lipoprotein. Cardiology 2015;132:27-33.

-33 Guri Y, Hall MN: mTOR Signaling Confers Resistance to Targeted Cancer Drugs. Trends Cancer 2016;2:688697.

-34 Zou Z, Chen J, Yang J, Bai X: Targeted Inhibition of Rictor/mTORC2 in Cancer Treatment: A New Era after Rapamycin. Curr Cancer Drug Targets 2016;16:288-304.

-35 Abeyrathna P, Su Y: The critical role of Akt in cardiovascular function. Vascul Pharmacol 2015;74:38-48.

-36 Heiss C, Rodriguez-Mateos A, Kelm M: Central role of eNOS in the maintenance of endothelial homeostasis. Antioxid Redox Signal 2015;22:1230-1242.

-37 Jin YP, Valenzuela NM, Ziegler ME, Rozengurt E, Reed EF: Everolimus inhibits anti-HLA I antibody-mediated endothelial cell signaling, migration and proliferation more potently than sirolimus. Am J Transplant 2014;14:806-819.

38 Aimi F, Georgiopoulou S, Kalus I, Lehner F, Hegglin A, Limani P, Gomes de Lima V, Ruegg MA, Hall MN, Lindenblatt N, Haas E, Battegay EJ, Humar R: Endothelial Rictor is crucial for midgestational development and sustained and extensive FGF2-induced neovascularization in the adult. Sci Rep 2015;5:17705.

-39 Barilli A, Visigalli R, Sala R, Gazzola GC, Parolari A, Tremoli E, Bonomini S, Simon A, Closs EI, Dall'Asta V, Bussolati O: In human endothelial cells rapamycin causes mTORC2 inhibition and impairs cell viability and function. Cardiovasc Res 2008;78:563-571.

-40 Yang C, Pan S, Yan S, Li Z, Yang J, Wang Y, Xiong Y: Inhibitory effect of 14, 15-EET on endothelial senescence through activation of mTOR complex 2/Akt signaling pathways. Int J Biochem Cell Biol 2014;50:93-100.

-41 Dormond 0, Madsen JC, Briscoe DM: The effects of mTOR-Akt interactions on anti-apoptotic signaling in vascular endothelial cells. J Biol Chem 2007;282:23679-23686.

-42 Yao Y, Wang Y, Zhang Y, Liu C: Klotho ameliorates oxidized low density lipoprotein (ox-LDL)-induced oxidative stress via regulating LOX-1 and PI3K/Akt/eNOS pathways. Lipids Health Dis 2017;16:77.

43 Chavez-Sanchez L, Espinosa-Luna JE, Chavez-Rueda K, Legorreta-Haquet MV, Montoya-Diaz E, BlancoFavela F: Innate immune system cells in atherosclerosis. Arch Med Res 2014;45:1-14.

44 Sharma S: Immunomodulation: A definitive role of microRNA-142. Dev Comp Immunol 2017;77:150-156.

45 Lagrange B, Martin RZ, Droin N, Aucagne R, Paggetti J, Largeot A, Itzykson R, Solary E, Delva L, Bastie JN: A role for miR-142-3p in colony-stimulating factor 1-induced monocyte differentiation into macrophages. Biochim Biophys Acta 2013;1833:1936-1946.

46 Liu Y, Song X, Meng S, Jiang M: Downregulated expression of miR-142-3p in macrophages contributes to increased IL-6 levels in aged mice. Mol Immunol 2016;80:11-16.

47 Sun Y, Varambally S, Maher CA, Cao Q Chockley P, Toubai T, Malter C, Nieves E, Tawara I, Wang Y, Ward PA, Chinnaiyan A, Reddy P: Targeting of microRNA-142-3p in dendritic cells regulates endotoxin-induced mortality. Blood 2011;117:6172-6183.

-48 Liu J, Li W, Wang S, Wu Y, Li Z, Wang W, Liu R, Ou J, Zhang C, Wang S: MiR-142-3p attenuates the migration of CD4 (+) T cells through regulating actin cytoskeleton via RAC1 and ROCK2 in arteriosclerosis obliterans. PLoS One 2014;9:e95514.

49 Bennett MR, Sinha S, Owens GK: Vascular Smooth Muscle Cells in Atherosclerosis. Circ Res 2016;118:692702. 